\title{
Influence of Organic Pollutants on Deterioration of Antique Glass Structure
}

\author{
E. Greiner-WronowA* \\ Faculty of Materials Science and Ceramics, Technical University of Science and Technology \\ al. A. Mickiewicza 30, 30-059 Kraków, Poland
}

\begin{abstract}
The state of glass artifacts preserved in museums is strongly dependent on strictly local parameters. The deterioration of antique glass brought on by organic compound activity which will receive attention in this work has been studied on a sample of a 18th c. glass beaker belonging to the National Museum in Kraków. Measuring of the corrosion was carried out on an original, as well as on a model (or sensor) glass. The former - the remains of an 18th c. beaker — was borrowed from the Museum. The latter is a modern sample. Both samples were tested with a non-destructive method. Glass sensors, the chemical composition of which corresponded to the analyzed objects, were prepared. Their purpose was to facilitate the study of corrosion induced by different chemicals and altered physical conditions, previously proved in the museum real circumstances. The chemical structure of glass before and after the induced corrosion processes in formaldehyde and acetic acid solution was examined by the Fourier transform infrared and Raman spectroscopy. Moreover, complementary tests by scanning electron microscopy, energy dispersive microscopy, confocal microscopy were carried out as well. The corrosion processes were realized by means of shock temperature changes, as well as altering of relative humidity. Parallel corrosion processes under halogen lamp radiation were also induced. Measurements of induced corrosion pointed to the fact that deterioration of glass depends not only on the concentration of corroding media, but also on thermal shock. An experiment involving the lighting of an object by halogen lamp isolated a very important agent, which has significant influence on glass deterioration. The intensity of the induced corrosion resulted, in some cases, in glass volume corrosion as well. The obtained information can be useful for curators and conservators, as any resulting glass changes are responsible for further, this time irreversible, alterations.
\end{abstract}

PACS: 81.05.Pj, 61.43.Fs

\section{Introduction}

Glass corrosion has been considered a process dependent on many factors. In the case of antique objects, the treatment by conservators must be well prepared, to avoid any further deterioration.

Ambient atmosphere consists of many chemical elements. Some of them exist in very small amounts, and that is why they are usually neglected. From the physical point of view, very small changes in the accepted exposition parameters can yield unpredictable effects. Thanks to the scientific cooperation between the National $\mathrm{Mu}$ seum in Kraków and AGH-Technical University of Science and Technology, some antique material deterioration problems have been taken into consideration. One of them, which is presented in this paper, has to do with the influence of organic compounds on glass deterioration. The process starts out as hardly visible surface changes, amounting to haziness of the glass (so-called "foggy glass"), or opaque deposits irregularly displayed on the glass. Organic pollutants are emitted from harl (chipboard) materials as compounds used for showcase production. We can mention mainly: formaldehyde, acetic acid and formic acid.

Due to their activity surfaces of glass become more or

* e-mail: egrwrona@agh.edu.pl less opacity or crystalline products such as alkali formats, or acetates are formed on the surface which had partially modified structure.

\section{Experimental}

To prove the presence of organic compounds inside the showcases, the measurements of formaldehyde concentrations were carried out. Measurements were carried out by colorimetric method. Formaldehyde was detected in the atmosphere inside the showcases [1, 2].

Our investigations were focused on one kind of glass, very well represented by the 18 th $\mathrm{c}$. glass beaker. Testing of antique glass was limited to a few fragments of the original antique glass.

More analyses were carried out on glass sensors, simulating the antique glasses. Their chemical composition was similar to the original ones, and the technological process is comparable to the one used previously. The sensors were prepared at the Materials Science and Ceramics Faculty, at AGH-Technical University of Science and Technology in Kraków. In this way, virtually unlimited amount of material can be delivered for experiments [1].

Corrosion of glass sensors was carried out by the following media: water, formaldehyde and acetic acid solutions of different concentrations in teflon containers.

To illustrate the real conditions, experiments in a few variants in different physical parameters were carried out. 
Experiments were divided into two groups, according to museum parameters.

One group was connected with changes of glass due to thermal shocks and media concentrations. The other one was carried out by means of thermal shocks and long lasting influence of radiance due to halogen lamp lighting. This last agent is very rarely emphasized as a reason of harmful influence on glass. The antique glass, as well as the glass sensor, was tested by scanning electron microscopy (SEM) and chemical analyzer (energy dispersive spectroscopy, EDS). Moreover, structural analysis was carried out by the Fourier transform infrared spectroscopy (FTIR), Raman spectroscopy (RS) and confocal microscopy. All of them are very well adopted methods of testing material in a non-destructive way. It should be emphasized that analyzed sample surfaces were not covered by carbon or gold. That is why the carbon detected on the surface must be connected with ambient elements, which react with glass. To predict the further consequences of such processes the glass sensor method has been applied. The sample lighting was realized by halogen lamp. The light intensity was measured by the device "luxmeter" (Kalibrier, type Testo 540) and expressed in lux.

The presence of organic compounds in museum showcases was confirmed by the colorimetric method. Measurements were done by testing atmosphere inside the showcases. The obtained formaldehyde concentration values varied from: 43.56 up to $175.50 \mu \mathrm{g} / \mathrm{m}^{3}$, in twelve chosen cabinets, at the constant background equal to $32.55 \mu \mathrm{g} / \mathrm{m}^{3}[1,2]$.

Our investigation of original glass was limited to one type of glass, dating back to the 18th c., and known as beaker glass, which belongs to the silica-potassiumcalcium system. Some fragments of antique glass were analyzed by non-destructive methods, namely: by SEM, EDS, energy dispersive X-ray spectroscopy (EDAX). SEM image is presented in Fig. 1.

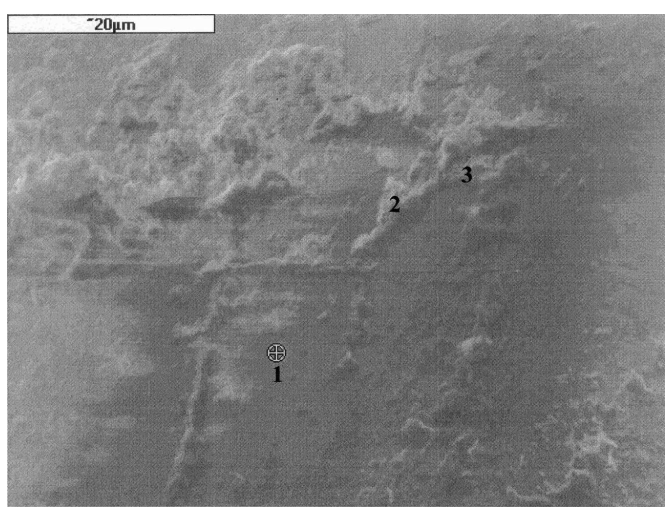

Fig. 1. SEM image of the original 18th c. glass.

For two chosen points, chemical analyses (EDS) was carried out. One of them is presented in Fig. 2.

It can be concluded that dealkalisation process has existed on the glass surface. The presence of large amounts

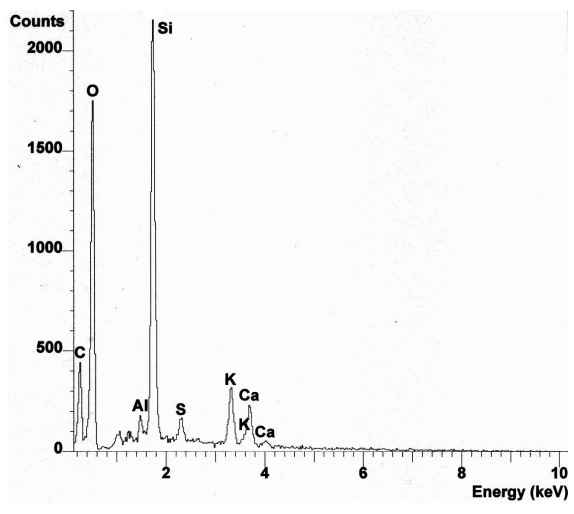

Fig. 2. EDS analysis for point 1, from Fig. 1.

of oxygen (which is not usually found in non-destructive glass) as well as large amounts of silica, confirmed the presence of silica-gel layer on the glass. Moreover, carbon, sulphur and chlorine originating from external circumstances were detected as well. Also, a part of the original glass fragment, was analyzed by FTIR - Fig. 3 .

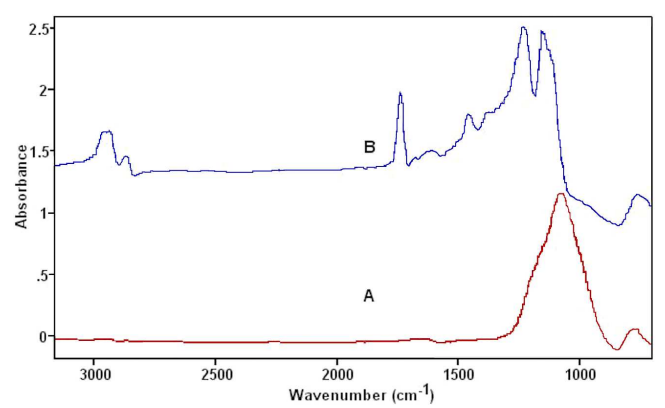

Fig. 3. FTIR spectra of original glass of the 18th c. glass - of chosen two places: $A$ - non-deteriorated area, $B$ - partly deteriorated area.

The two spectra obtained belong to: $A$ - not deteriorated area and $B$ - partly deteriorated area. Spectrum $A$ refers to a hardly corroded area, but without structure deformation. Actually observed in microscopy tiny cracks refer only to sample surface. Spectra $B$ from this area pointed to organic inclusion - band at $1740 \mathrm{~cm}^{-1}$ according to $\mathrm{C}=\mathrm{C}$ vibration and in the range $2800-3000 \mathrm{~cm}^{-1}$ according to $\mathrm{C}-\mathrm{H}$ vibration. Moreover, significant changes are visible at $1000-1300 \mathrm{~cm}^{-1}$. This suggests some changes in glass structure, due to the beginning of these corrosion process.

To create the possibility of further comparative analysis, and explain deterioration on historical glass, experiments with glass sensors were set up.

Glass for the experiments presented in this paper was prepared on the basis of chemical composition of the 18th c. glass beaker, which has already been discussed. The beaker belongs to $\mathrm{Si}-\mathrm{K}-\mathrm{Ca}$ system.

The prepared glass sensors were used for inducing artificial corrosion. In this way, the alteration procedure 
could be analyzed as a function of time, temperature, humidity, lighting, radiation and pollutant concentrations, on unlimited material. Experiments were carried out with the use of the following media: water, formaldehyde and acetic acid of different concentrations, in teflon containers. To simulate real conditions, a few variants of the experimental conditions were planned. Experiments were divided into two groups, according to external parameters.

One group was connected with observation of glass changes due to thermal changes and media concentrations. The other one was carried out by means of thermal changes and long term influence of regular radiance, due to lighting by halogen lamp. This last agent is very rarely emphasized as a reason of harmful influence on glass. All our experiments were carried out in severe conditions, in highly concentrated corrosive solutions.

Two distinct glass alteration processes can occur in a solution. They are both very much dependent on solution $\mathrm{pH}$. Water solution induces the leaching process, causing the removal of metal ions (alkali) from the glass structure and delivering $\mathrm{H}_{3} \mathrm{O}^{+}$ions from the water [1]. Actually, during leaching, three reactions take part in the corrosion process, and they occur simultaneously. They are: ion-exchange, hydration and hydrolysis [1,3]. All of them have influence on one another. Deterioration, first of all depends on the quality of the glass.

The kinetics of network hydrolysis depends on both the distribution of local units in the glass structure and on the chemical composition of the solution [3-6]. The latest should be taken into consideration in the case of three different organic media reacting with one kind of glass. The resulting changes of the glass altering process were compared with the non-altered one.

\section{Glass degradation by organic compounds enhanced by shock temperature}

To check the influence of the arranged temperature changes on the deformation of corroded glass structure, the following experiments were carried out. The glass sensor prepared for the 18th c. glass was cut into smaller fragments. One side of each sample was sanded. Samples were immersed in five media: sample no. 1: $40 \%$ acetic acid; sample no. 2: $80 \%$ acetic acid; sample no. 3: $20 \%$ formaldehyde; sample no. 4: $38 \%$ formaldehyde; sample no. 5: distilled water; sample no. 6: "standard". This group of experiments was focused on the estimation of thermal gradient on glass structure changes. Samples were boiled at $98^{\circ} \mathrm{C}$, every 7 days, and the rest of the exposition was done at room temperature, over a period of 6 months.

The sample weight and sensor surface state were analyzed after each stage of the experiments. The glass sample weights were not significantly differentiated. The visible changes were observed on the sample surface in samples 3 and 4 . They both referred to formaldehyde activity, but of different concentrations.
The surface of glass 3 after 6 month activity of $20 \%$ formaldehyde solution is visible in the SEM image in Fig. 4.

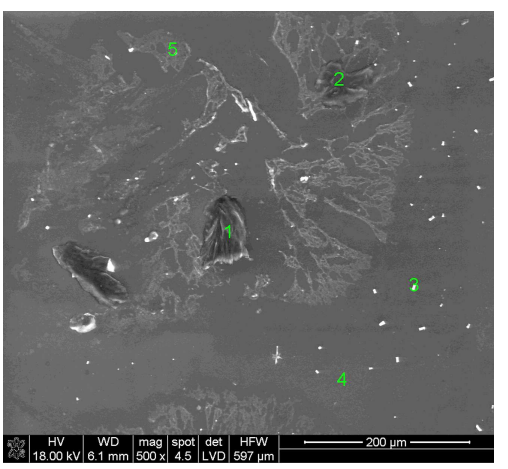

Fig. 4. SEM image of sample no. 3 in $20 \%$ formaldehyde.

The carbon indicated by EDS spectra, after a few month formaldehyde activity, suggested formation of organic deposit on the glass surface. It is related to crystallization due to reaction of formaldehyde with released alkali ions from glass and created formates, which was found in literature as well [4]. After the experiment, the sensor was tested by micro-Raman spectroscopy ALMEGA XR Dispersive, with high distribution ability and with laser giving visible length of $785 \mathrm{~nm}$ and $532 \mathrm{~nm}$, with objective $\times 10$ or $\times 100$. The length of unit exposition was $5 \mathrm{~s}$, by number of registered explosives: 32 .

Sample 3 pointed to white deposits on the sanded surface - Fig. 5. The non-sanded side was not changed.

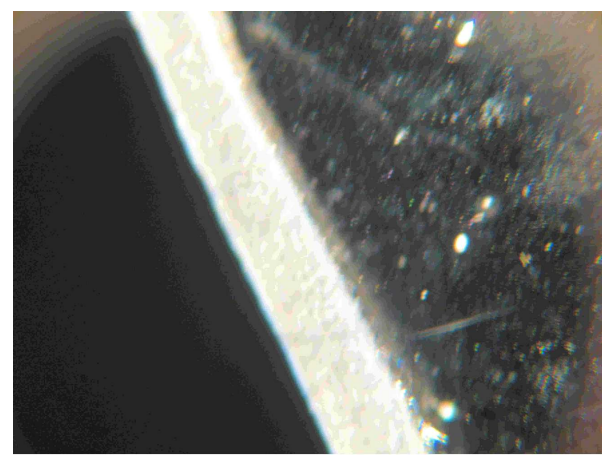

Fig. 5. NEOFOT picture of sample no. 3 .

EDAX testing of sample 3 pointed to high concentration of carbon in average surface analysis. Moreover, RS testing showed small changes in spectra - Fig. 6 in comparison with the "fresh", non-corroded sample - Fig. 7.

The Raman spectra for the altered sample are presented in Fig. 6, including the set of peaks recorded in the analysis.

For "fresh", non-altered glass, the Raman spectra including the set of peaks appearing by analyzing procedure are shown in Fig. 7. 


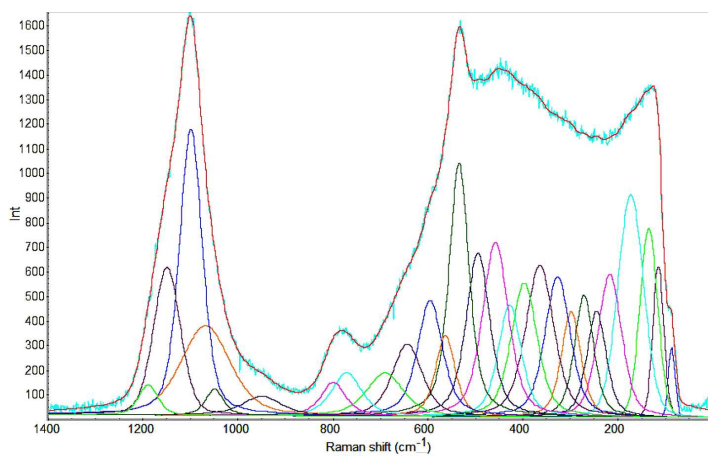

Fig. 6. RS spectra of sample no. 3 boiled in $20 \%$ formaldehyde.

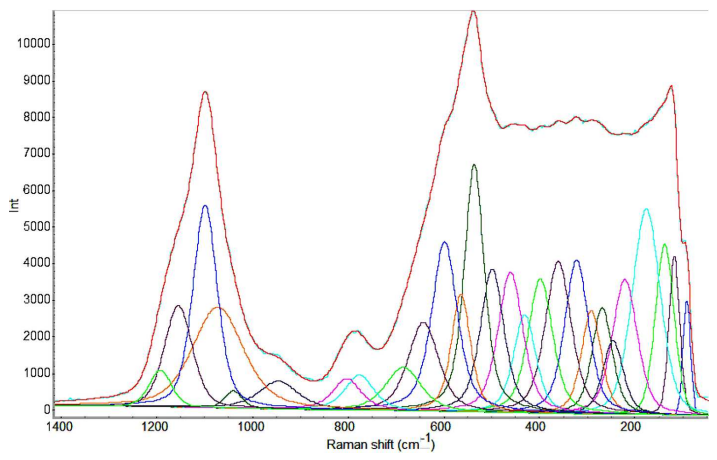

Fig. 7. RS spectra of "fresh", non-corroded glass sensor of the 18 th c. beaker.

Consequently, after comparing data for both samples, repeating values of presented bonds were excluded. Only new peaks (new values) were taken into consideration. They were the confirmation of the changes that took place due to the corroding process induced with formaldehyde. Part of them were adjusted to potassium formate $[4,7]$. The spectra were measured in the range of 50 $1400 \mathrm{~cm}^{-1}$. The band resolution ability was $c a .2 \mathrm{~cm}^{-1}$. Frequency for potassium formate was in accordance with sodium, and was fitted on the basis of data for sodium formate.

In contrast to data for the sodium formate, all bands for potassium formate were shifted, due to different mass values between potassium and sodium. To get better information, the exposition time of the glass sensor should be left to age for a longer time, including halogen lamp radiation directed on sample.

In the case of stronger formaldehyde solution (38 of \% weight), results were more visible, which was confirmed by EDAX analysis - Fig. 8 .

The next sensor was immersed in acetic acid. Sample no. 1 after long time exposition in $40 \%$ acetic acid, and occasionally boiling was covered by very tiny white deposit, but only on the sanded surface. EDS measurements proved domination of the carbon component. Additional testing by the Raman spectroscopy was approved to better identify the created product.

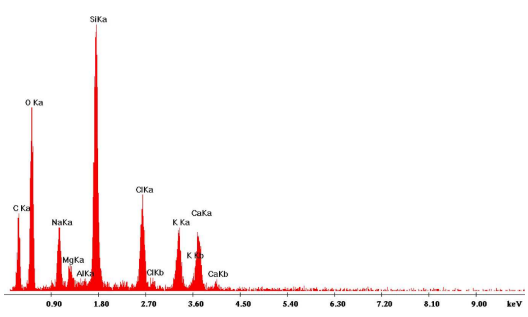

Fig. 8. EDAX analysis for sample no. 3.

The Raman spectroscopy provides important information, not only about molecular structure of objects, but also about the emergent glass corrosion crust. The observed surface is presented in Fig. 9.

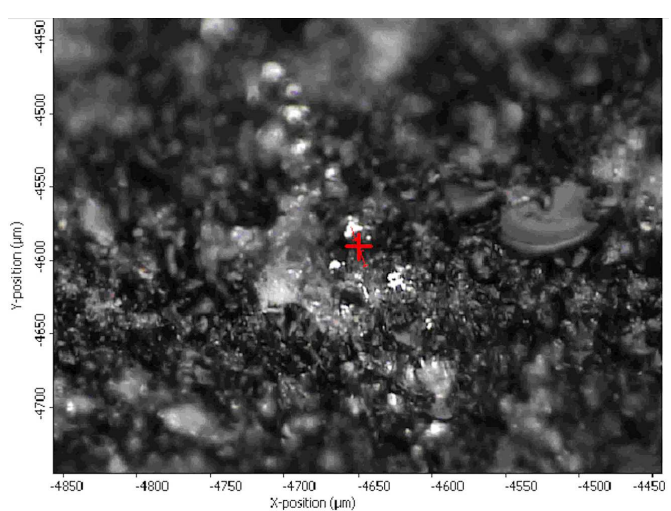

Fig. 9. RS microscope picture for sample corroded in $40 \%$ acetic acid.

To analyze the influence of time on glass deterioration in the case of these media, spectra corroded over a period of three months (sample $a$ ), was compared with the other one, and corroded over a period of six months - sample $b-$ Fig. 10 .

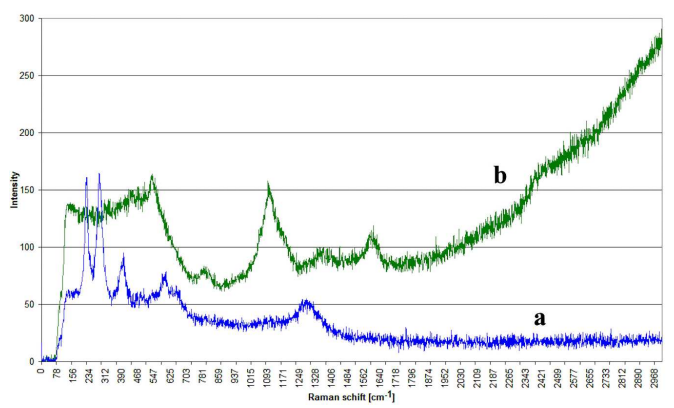

Fig. 10. RS spectra of sample corroded in $40 \%$ acetic acid: $a$ - for 3 months, $b$ - for 6 months.

The spectra obtained in Fig. $10 a$, pointed to a rocking bond at $471 \mathrm{~cm}^{-1}$, belonging to $\mathrm{COO}$, at $596 \mathrm{~cm}^{-1}$ rocking bond for $\mathrm{COO}$ and at $650 \mathrm{~cm}^{-1}$ deformation vibration from COO. All of them belong to potassium acetate, which was created due to acetic acid activity. After 
longer exposition (6 months), next measurements by RS were carried out. They pointed to higher intensity of the emergent deposit. It is presented in Fig. 10b. The following bonds have been identified: at $1100 \mathrm{~cm}^{-1}$ for potassium rocking vibration, at $1352 \mathrm{~cm}^{-1}$ for the deformation vibration and at $1589 \mathrm{~cm}^{-1}$ for the stretching vibration bond for $\mathrm{C}-\mathrm{O}$ (Fig. 10b) [6]. The glass contained potassium, which came out due to the leaching process and joined with groups of $\mathrm{CH}_{3} \mathrm{COO}^{-}$from the acetic acid solution and created $\mathrm{KCH}_{3} \mathrm{COO}$ (potassium acetate). Interestingly enough, potassium carbonates are absent from the surface. Moreover, FTIR measurements by FTS 60 Spectrometer with $4 \mathrm{~cm}^{-1}$ resolution were carried out for all tested sensors.

After the experiment, each sample was analyzed Fig. 11. Sample 6 called "standard" was made of clean glass without any deterioration and was measured for comparison with the corroded ones.

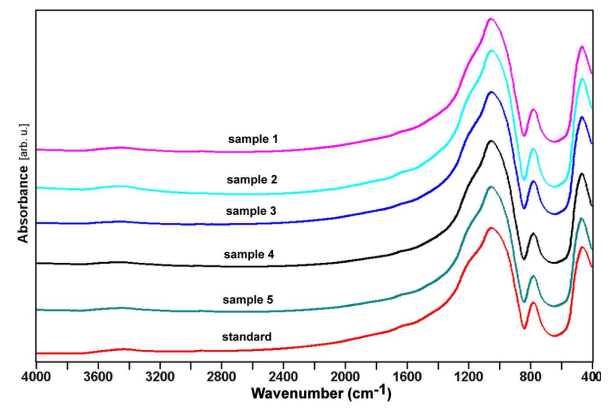

Fig. 11. FTIR spectra of samples 1-6.

The material for FTIR analysis was prepared from sensors after cleaning their surface. Samples were uniformed by very precise mixing. The measurements were carried out three times. All obtained spectra have the same bands, there are no differences among them. It means that all of them represent unchanged glass structure.

The observed bands: rocking at $474 \mathrm{~cm}^{-1}$, bending at $778 \mathrm{~cm}^{-1}$, bond stretching at $1060 \mathrm{~cm}^{-1}$ of $\mathrm{Si}-\mathrm{O}$ group [6], are considered as the main bands typical for standard silica glass structure. On all spectra a weak band about $3420 \mathrm{~cm}^{-1}$ is visible. It is connected with $\mathrm{OH}$ stretching vibrations due to water or $\mathrm{H}_{3} \mathrm{O}^{+}$ions penetration - Fig. 11 [6].

The rest parts of the spectra are without visible changes. It can be suggested that there are no structural changes over $1 \%$ (which is equal to equipment accuracy) in comparison with the standard sample.

\section{The corrosion process enhanced by temperature shock and long term lighting radiation}

The next group was referred to induced corrosion, a process accelerated by high temperature changes and lamp lighting directed on tested sensors $[7,8]$.
Two samples: $A$ and $B-$ glass sensors with the same compositions as the material in the previous testing group - were immersed in $20 \%$ formaldehyde solution in separate teflon containers. Sample $A$ was ground on one side and immersed in a formaldehyde solution. Sample $B$ — without any sanding — was first altered by exposure in water for 7 days at room temperature and later boiled at $98^{\circ} \mathrm{C}$ for $2 \mathrm{~h}$. Then, sample $B$ was immersed in $20 \%$ formaldehyde and altering as sample $A$ at: room temperature and occasionally exposed on the lighting radiation by the halogen lamp - intensity 1500-2000 lx. The brightness was measured at the end of the each lighting term. The experiment was carried out over a period of 6 months.

Sample $A$ was kept at room temperature, but $B$ was also occasionally boiled at $98^{\circ} \mathrm{C}$ for a total of $66 \mathrm{~h}$. Total lighting time for $A$ and $B$ was $228 \mathrm{~h}$. After the first part of the experiments it was concluded that - after 3.5 months - the surface of sample $A$ was without any changes, but surface of sample $B$ was slightly changed, with a few points with small crystalline deposit, presented on SEM - Fig. 12.

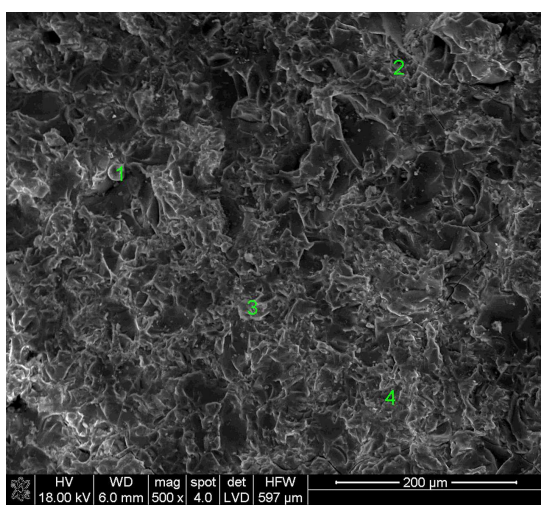

Fig. 12. SEM image of sample $B$.

Chosen points in this image confirm the presence of silica gel, by EDS - Fig. 13. An area with high carbon concentration was found as well - Fig. 14.

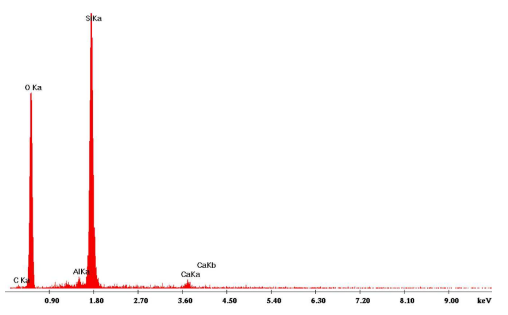

Fig. 13. EDS analysis of sample $B$ p. 1 from Fig. 12 .

The experiments were then extended for the following 3 months. The effect of these 6 months of expositions is presented in Fig. 15.

The surface parts, which were "fresh" after cutting from a larger one, corroded first and reached deeper glass lay- 


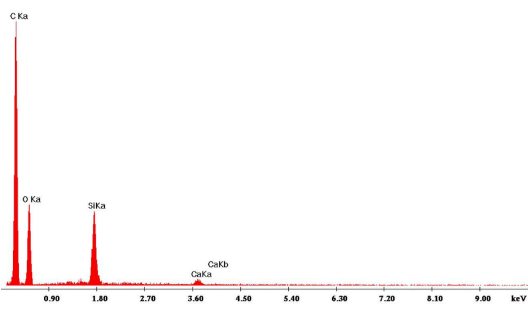

Fig. 14. EDS analysis of sample $B$ p. 2 from Fig. 12 .

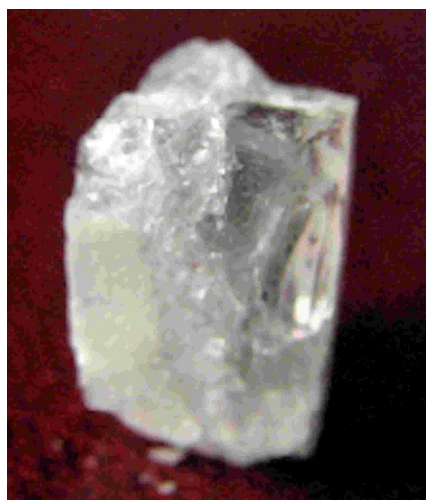

Fig. 15. Picture of macroscopic observation of sample $B$.

ers than other parts of the sensor. They were corroded and white deposits were created. Their morphology was analyzed by confocal microscopy — LEXT Olympus OLS 3100. The results obtained are presented in Fig. 16 and in Fig. 17. Due to the emergent surface changes, differences between the highest and the lowest point of the surface can be calculated and defined as a "roughness". For desiring of other values, which would describe the corrosion phenomenon, this is an important feature.

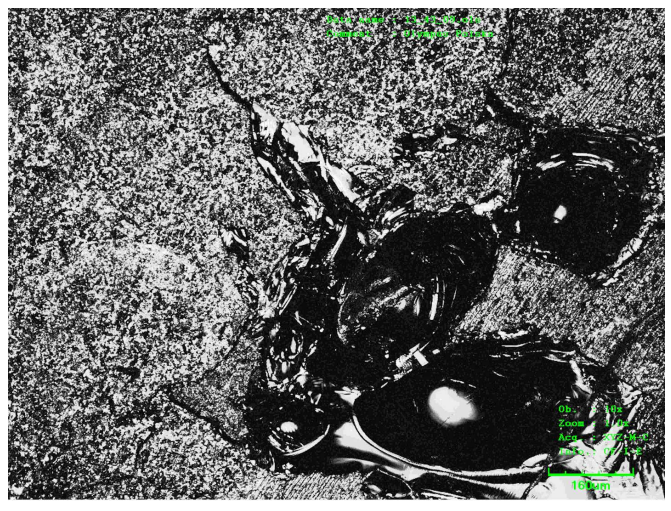

Fig. 16. Confocal microscopy image of sample $B$.

Its observed chosen area is presented in Fig. 18, where roughness is $c a .89 .7,130.8,220.5 \mu \mathrm{m}$. There are also areas like these presented in Fig. 19, where roughness values are: $11.2,13.8,25.0 \mu \mathrm{m}$.

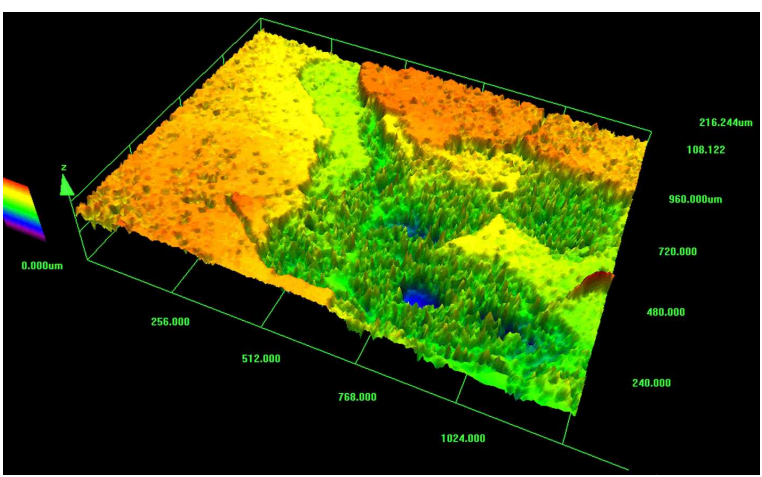

Fig. 17. Confocal microscopy image of sample $B$.

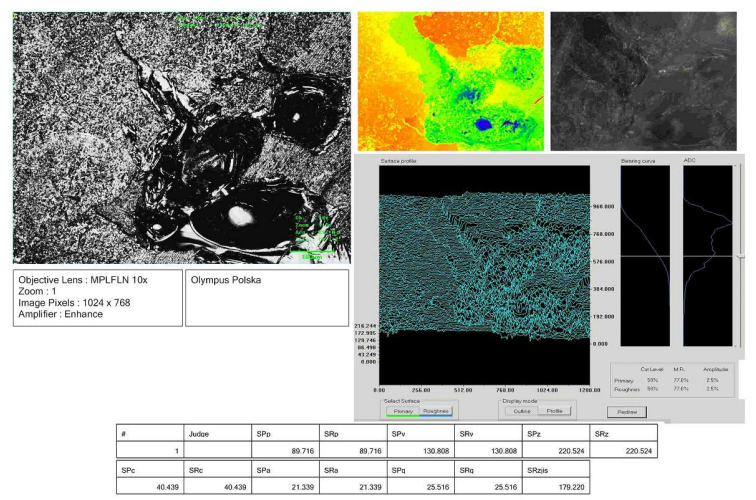

Fig. 18. Roughness of sample $B$.

Sample $A$, which was not altered before, and not boiled during the experiment, looks much better. It has some mechanical cracks, in the middle part, but other areas are almost untouched. Calculated roughness is presented in Fig. 20, where there are following values: 13.4, 13.8, $27.3 \mu \mathrm{m}$. For further testing, sensor $B$ was chosen for structural testing by FTIR. It was very much deteriorated, which is emphasized in Fig. 21. Measurements were carried out separately for: $a$ - the destroyed surface layer (with white deposit), $b$ - layer between cor-

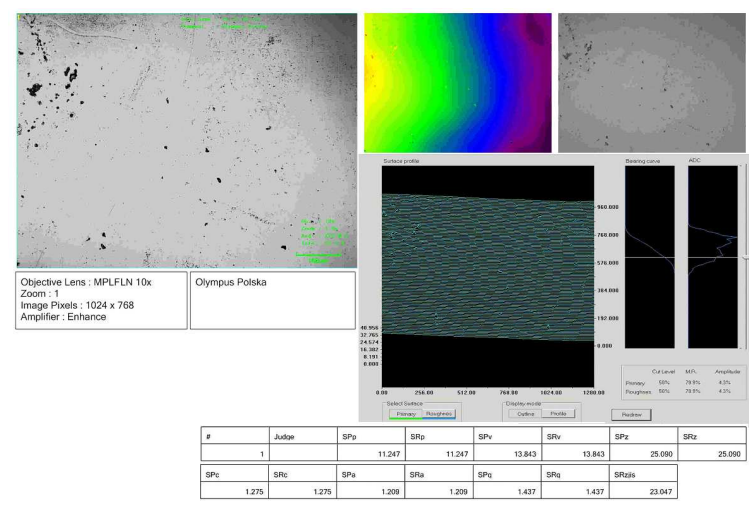

Fig. 19. Roughness of sample $B$. 


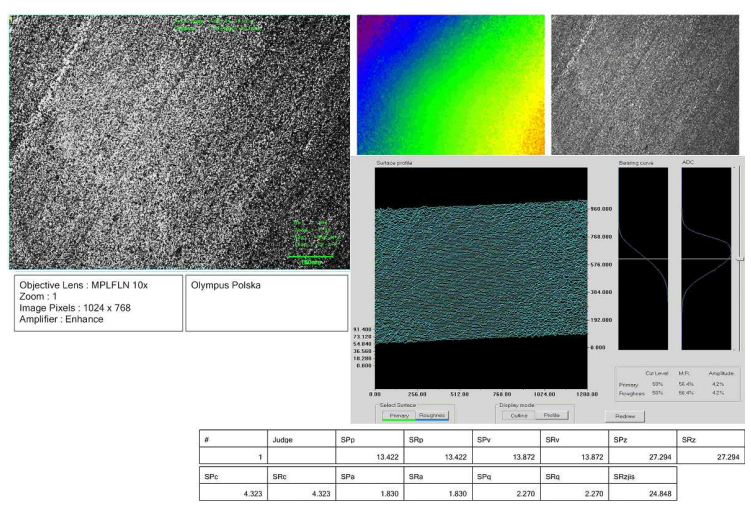

Fig. 20. Roughness of sample $A$.

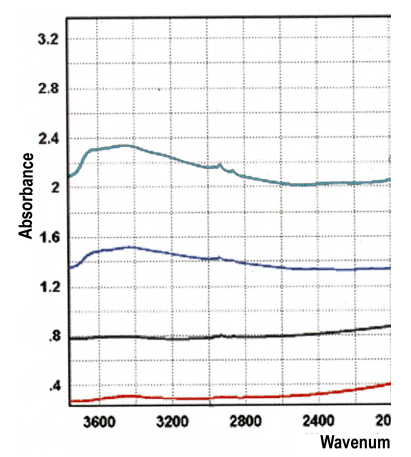

Fig. 21. FTIR spectra of the corroded sample $B$.

roded surfaces and bulk, $c$ - bulk glass, $d-$ standard glass. The obtained data are presented in Fig. 21.

These three spectra for altered glass sensors, were compared with the "standard", or the clean, non-altered glass sensor. FTIR spectra are presented in Fig. 22.

More changes, better visualized in Fig. 22 have occurred at $700-1600 \mathrm{~cm}^{-1}$. First of all, standard glass (spectrum $d$ ) is different from spectra: $a, b, c$. Typical silica glass bands in the spectra $a, b, c$ are more or less shifted in comparison to standard data (spectrum $d$ ). In the range $780-800 \mathrm{~cm}^{-1}$ there is visible bending from $780 \mathrm{~cm}^{-1}$ (for spectrum $d$ ) to $790 \mathrm{~cm}^{-1}$ (for spectrum $a$ ).

The silica-oxygen band at $1060 \mathrm{~cm}^{-1}$ for the standard glass (spectrum $d$ ) is changed after deterioration and transformed to the doublet silica-oxygen at 990$1056 \mathrm{~cm}^{-1}$ for spectrum $c$. This indicates changes in a bulk of glass sample. Due to formaldehyde activity visible structure destruction has occurred, going through $1068 \mathrm{~cm}^{-1}$ for spectrum $b$ and reaching stretching vibration $\mathrm{Si}-\mathrm{O}$ at $1080 \mathrm{~cm}^{-1}$ for spectrum $a$. These changes caused some surface destruction, resulting in the emergence of the surface white product (presented in Fig. 15) and creating a vibration from $\mathrm{C}=\mathrm{O}$ (carboxyl group) at $1742 \mathrm{~cm}^{-1}$ [9].

The next range with visible developing changes is at $2800-3000 \mathrm{~cm}^{-1}$. It can only be found in spectrum $a$, which refers to the biggest deterioration layer (white de-

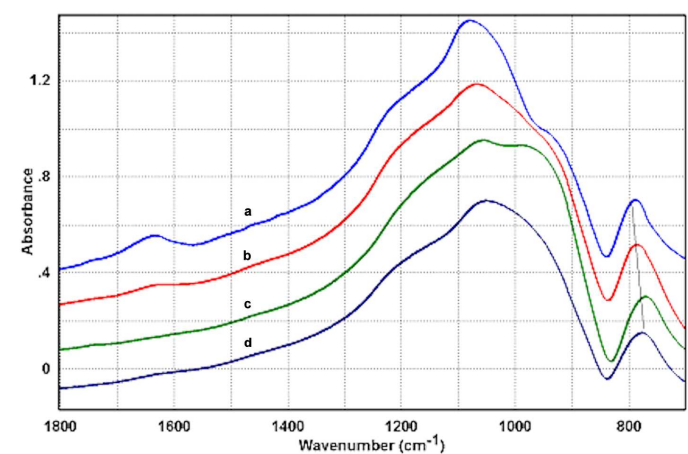

Fig. 22. FTIR spectra of sample $B$ in the range of $800-$ $1800 \mathrm{~cm}^{-1}$.

posit). These are bands belonging to $\mathrm{C}-\mathrm{H}$ stretching vibration from the $\mathrm{CH}_{3}$ and $\mathrm{CH}_{2}$ groups.

Additionally, these are presented bands of water at $3400 \mathrm{~cm}^{-1}$, as well as at $1640 \mathrm{~cm}^{-1}$. Because of the reaction between weak, silica-potassium glass and formaldehyde, potassium formate has been created. There is the probability of existing bands of potassium formate, hidden under intensive band from silica. As for example: around $1050 \mathrm{~cm}^{-1}$ from $\mathrm{H}-\mathrm{C}-\mathrm{H}, 930 \mathrm{~cm}^{-1}$ from stretching vibration from $\mathrm{C}-\mathrm{C}$, these bands could exist.

\section{Discussion results}

All of the experiments with artificial corrosion of the 18th c. potassium glass pointed to its susceptibility to reaction with organic media. The formation hardly visible or even thicker deposit on glass surfaces implies that in museum circumstances the glass has reacted with its environment. Consequently, its chemical structure has been modified. It is started from the surface and gradually developed, reaching bulk of glass. It is dependent on many factors, chemical and physical. The problem of organic compounds was mainly studied in this paper. There are no rules according to which kind of volatile organic compounds (VOCs) should be used. The presence of formaldehyde has been proved by analysis of VOC in museum showcases $[1,2]$.

Formaldehyde and acetic acid were applied to carry out experiments with inducing corrosion. They were used at different concentration.

The alteration process of glass exposed to a humid acidic atmosphere was different from that in a humid "unpolluted" one. As a result, the structure of the altered layer was differentiated. The differences between these two alteration processes and their impact on the structure were presented.

The difference in acidity of formic acid and acetic acid solution may be the reason for the predominance of formate crystals on the glass surface, despite the fact that the acetic acid was present at higher concentrations.

The formic acid is more strongly dissociated than acetic acid, at a given molar acid concentration in an 
aqueous solution. It generates a higher concentration of $\mathrm{H}^{+}$ions. However, the acid reacts with alkali ions (in this case, with potassium leached from glass), to form small crystalline deposits, creating a strong equilibrium towards increased ion exchanges. Earlier tested samples of glass sensor of the 18th c. object, temporary boiled at $98^{\circ} \mathrm{C}$ pointed to similar changes $[9,10]$. Formaldehyde undergoes oxidation and creates carboxyl acid as follows:

$$
\begin{aligned}
& \mathrm{HCOH}+\mathrm{HCOH} \stackrel{\mathrm{H}_{2} \mathrm{O}}{\longrightarrow} \mathrm{HCOOH}+\mathrm{CH}_{3} \mathrm{OH} \\
& \text { formic acid }+ \text { methyl aldehyde }+ \text { alkali } \\
& \qquad \rightarrow \text { formates } \mathrm{HCOO}(\mathrm{K}, \mathrm{Na})
\end{aligned}
$$

During alkali glass corrosion in water solution, the process of leaching has occurred. Consequently, potassium ions, which come out of the glass due to leaching alkali, created $\mathrm{COOH}^{-}$; they both joined together forming potassium formates HCOOK. Potassium was found in corrosive solution by the inductively coupled plasma (ICP) method in previous research [1, 9], and probably comes into reaction with formic acid, giving it some amount of potassium formates [2, 5]. Formaldehyde vapours emitted from the museum showcase shelves in the exposition and storage hall are responsible for the glass corrosion.

Acetic acid creates very tiny changes, which result in surface local opacity but exposition in more severe conditions created a potassium acetate. But after exposition in more severe conditions it produced potassium acetate. The EDS analysis results pointed silica gel and sometimes carbon presence on the glass surface. It is in accordance with earlier experiments when optical interferometer measurements showed the tiny pit corrosion $[1,2,9]$. It was a reason to create fogginess on the surface. The process was accelerated by boiling, lighting (radiation) or extended time of exposition, induced progressing of this destruction process, finally causing some corrosive surface products as well.

In the case of formaldehyde activity, a small white deposit is very quickly created. It is due to the hydroxylation of silica on the surface. This caused the creation of silanol groups. These can bind with organic particles and polymer groups. Alkali leached from glass are joined with organic compounds. Formaldehyde has very high reactivity and ability of spontaneous polymerization, resulting in "paraformaldehyde" formation. This can occur even at low temperatures. After heating, it could depolymerize into gas phase-formaldehyde. But in the meantime, due to presence alkali in the solution (potassium or sodium) formates are created [9].

The identification of a very tiny crystal deposit is difficult, because of the size and/or heterogeneity of the tested sensor. The Raman spectroscopy is a very adequate piece of equipment to test such parameters. The Raman spectroscopy is a complementary technique, which helps to define very tiny deposits on the surface in a non-destructive way. The obtained data help to better interpret data from EDAX analysis.
Finally, it should be pointed out that in some cases, organic compounds could have originated from conservators' activity, or from organic paints used for glass decoration.

\section{Conclusions}

- Altered glass surface has a greater tendency to react with environmental agents. Moreover, the corrosion process is dependent on the quality of the glass (or its chemical composition) and surrounding parameters, mainly humidity and local lighting. Long term activity of organic compounds accelerates even tiny local destruction and reaches structure destruction. The level of deterioration is also connected with the time of activity.

- The organic media were used with higher concentrations than those in existence in museums. The obtained results emphasize that organic media enhance corrosion of unstable glass at higher relative humidity.

- Reaction with acetic acid caused silica-gel creation on the glass surface and more or less advanced weathering, gradually reaching the point of the emergence of white deposit.

- Glass reacting with formaldehyde solutions initiates formaldehyde polymerization or depolymerization according to ambient conditions. White deposit on the glass surface is gradually developed. Due to the reaction in water, the solution silica-gel layer is formed, too.

- The experiments point that organic compounds react with glass surface film, producing negligible effects. But due to extended time of corrosion or inducing gradient of the temperature or lighting directed on the object, the accumulation of deterioration effects is more visible.

- The tendency of organic products to depolymerize (by deliquescence) is connected with the relative humidity in the surroundings. Generally, they are changed during the winter. That is why all unstable glasses must be under very special control to avoid additional deterioration.

- The morphology changes on glass in case of formaldehyde activity could be caused by season parameters changes in the closest environment, responsible for gradients of temperature.

- The Raman spectroscopy has not pointed to carbonate compounds as corrosion products. It is important information for conservators, urging them to change some of their habits. More often chlorine compounds were presented, which was confirmed by EDS or EDAX measurements. 
- Glass corrosion started from the surface going into volume of glass, although only deteriorated surfaces confirmed the high level of corrosion destruction. But due to the Raman spectroscopy and FTIR measurements glass structure deterioration has been proved.

- This experiment emphasized that even severe conditions (like boiling with consequences) sometimes were not enough to destroy silica-oxygen bounds. But long term lighting (radiation) directed on the object caused bulk structure deterioration i.e. beginning volume corrosion. Visible structure changes of bulk glass were confirmed by FTIR spectroscopy measurements.

- This fact confirms how harmful are all kinds of lamps and sun to antique objects, which usually are not in a very good condition to begin with, and often are already seriously corroded. Light sources create new energy and have influence on changeable relative humidity values.

- The results of the experiments with differentiated values of relative humidity at some estimated organic compound concentrations should be used to plan sustainable conservation for unstable historical glass.

- Unstable museum parameters, especially irregularities with average relative humidity (between sum- mer and winter) could be a reason why regular cycles of crystallization and deliquescence of surface formates come to be.

\section{References}

[1] E. Greiner-Wronowa, Ceramics, Pol. Ceram. Bull. 85, 237 (2004) (in Polish).

[2] E. Greiner-Wronowa, A. Pusoska, Biuletyn informacyjny konserwatorów dzieł sztuki 15, 26 (2004) (in Polish).

[3] B.C. Bunker, J. Non-Crystalline Solids 179, 300 (1994).

[4] L. Robinet, K. Eremin, B. Cobo, del Arco, L.T. Gibson, J. Raman Spectrosc. 35, 662 (2004).

[5] R.L. Frost, J.T. Kloprogge, J. Mol. Struct. 526, 131 (2000).

[6] M. Handke, W. Mozgawa, J. Mol. Struct. 325, 129 (1994).

[7] K. Barczak, T. Pustelny, D. Dorosz, J. Dorosz, Europ. Phys. J.-Spec. Top. 154, 11 (2004).

[8] E. Macial, Z. Opilski, T. Pustelny, M. Bednorz, J. Phys. IV (France) 129, 131 (2005).

[9] E. Greiner-Wronowa, A. Pusoska, Ann. Chim. 96, 623 (2006).

[10] E. Greiner-Wronowa, L. Stoch, Glass Technol. 43C, 84 (2002). 